\title{
A Study of the Chinese-English Translation of Culture-specific Items in Publicity Texts of Guangzhou's Intangible Cultural Heritage
}

\author{
Shaohui Zheng \\ School of Foreign Studies, Guangdong University of Petrochemical Technology, Maoming, Guangdong, China
}

\begin{abstract}
Intangible cultural heritage is the core of Guangzhou's cultural "soft power". The Chinese-English translation of intangible cultural heritage is an important way to promote Guangzhou's culture and to arouse the awareness of protecting intangible cultural heritage in the whole society. The culture-specific items in the publicity texts of intangible cultural heritage reflect the charm and heterogeneity of Guangzhou's culture. This paper proposes that while translating cultural-specific items of Guangzhou's intangible cultural heritage, in order to ensure that the translation can retain the cultural characteristics of the source language and be understood and accepted by the target language readers, translators should combine the translation strategies of Domestication and Foreignization and flexibly adopt seven methods, i.e., literal translation, literal translation plus transliteration, literal translation plus explanation, transliteration plus explanation, transliteration plus category words, transliteration plus intra-text explanation and transliteration plus free translation. Suggestions are also given aiming to provide reference for the researches and practice of the translation of intangible cultural heritage in Guangzhou and other cities. It is also hoped that this study can provide some implications for pedagogical application and be helpful for those who follow closely the translation of intangible cultural heritage.
\end{abstract}

Index Terms - culture-specific items, intangible cultural heritage, translation, foreignization, demestication

\section{INTRODUCTION}

Culture is the soul of a nation, and intangible cultural heritage is the foundation of the "cultural soft power" of a country or a region. As an important carrier of national traditional culture, intangible cultural heritage represents the spiritual personality of different cultural groups. As an ancient civilization with a history of 5,000 years, China has 42 items selected into the UNESCO Intangible Cultural Heritage List, ranking first in the world. Guangzhou, a strong economic and cultural city in China, has so far altogether 2 items listed on UNESCO Human Intangible Cultural Heritage, 16 items listed on National Intangible Cultural Heritage and 30 items listed on Provincial Intangible Cultural Heritage, ranking among the top in China.

Guangzhou is a core city of Pearl River Delta economic zone and the Belt and Road in South China. Intangible cultural heritage, as the core of "cultural soft power" demonstrating the cultural quality and spiritual outlook of a city, plays a crucial role in the external publicity of Guangzhou. Therefore, the translation quality of intangible cultural heritage in Guangzhou has become increasingly important. This paper, focusing on the culture-specific items in publicity texts of Guangzhou's intangible cultural heritage, first explores the Chinese to English (C-E) translation methods by combining the strategies of Domestication and Foreignization, and then gives some suggestions on the translation practice and studies on the C-E translation of Guangzhou's intangible cultural heritage accordingly. It is hoped that this study can provide reference for the researches and practice of the translation of intangible cultural heritage in Guangzhou and other cities, provide some implications for pedagogical application and be helpful for those who follow closely the translation of intangible cultural heritage.

\section{LITERATURE REVIEW AND THEORETICAL FRAMEWORK}

\section{A. Previous Studies of Domestication and Foreignization}

Friedrich Schleiermacher, a famous German linguist, proposes two ways for translation in his book On the Different Methods of Translating - alienating and naturalizing. Alienating means making the study remain there and leading readers to approach the study while naturalizing means making the study approach readers and readers remain there (Schleiermacher, 1992). Andre Lefevere puts it the other way as "either the translator leaves the study in peace, as much as possible, and moves the reader towards him; or he leaves the reader in peace, as much as possible, and moves the study towards him" (Lefevere, 1992). Inspired and influenced by Schleiermacher and Lefevere, Laurence Venuti, an American theorist, proposes the Domestication and Foreignization strategies for the first time in his monograph The Translator is invisibility-A History of Translation in 1995. As for Domestication, Venuti argues that it is "an illusionism produced by fluent translating. The translator's invisibility at once enacts and masks an insidious 
domestication of foreign texts, rewriting them in the transparent discourse that prevails in English and that selects precisely those foreign texts amenable to fluent translating". Wang Dongfeng (2002) summarizes that the definition of Domestication defined by Venuti as below: it complies with target language's culture and current mainstream values by adopting the conservative assimilation method of the source text, in order to cater to the local law, publishing trend and political demand (Chen, 2018).

The characteristics of Foreignization are just opposite to those of Domestication. Domestication focuses on how to make readers understand the translation, while Foreignization emphasizes how to retain characteristics and integrity of the source text. Venuti (1995) proposes that "a Foreignization method is an ethno deviant pressure on those values to register the linguistic and cultural differences of the foreign text, sending the readers abroad". And he states that foreignizing translation signifies the difference of the foreign text only by disrupting the cultural codes prevailing in the target language (Venuti, 2001). Culture is an important "soft power" of a country and the real purpose of cross-cultural communication is to recognize and learn cultural differences. Venuti emphasizes the importance of keeping the foreignness in the target text, holding that even the translated text could be readable for only a small amount of well-educated people, and thus the translator should try to preserve the linguistic and cultural features of the source text to recognize and learn the differences in foreign language and culture, like sending the readers "abroad" (Chen, 2018). Guo Jianzhong (2000) holds that Venuti tries to put the translation theory of deconstructionism into practice and proposes the strategy of "resistant translation" against the traditional "smooth translation", which aims to reverse the colonial concept of translation, the English-American culture centralism and the value of imperialist culture ideologically. Therefore, proper translation principles and methods should be adopted to preserve "foreignness" instead of seeking "similarity." At the same time, The Dictionary of Translation Studies defines Foreignization as maintaining foreignness of the source language to some extent by deliberately using the unconventional translation methods to translate the target language (Shuttleworth, 1997).

To conclude, Domestication advocates that the target language readers should come first. The translation should conform to the mainstream values, political needs and social norms of the target language countries, and its quality depends on the degree of acceptance by the target language readers. Foreignization advocates that the source language culture should come first. The translation should retain the foreign characteristics of the source language culture. Foreignization is not only conducive to the external dissemination of local culture, but also enriches the language and culture of the target language and promotes intercultural communication and integration, which is in line with the developing trend of the new era. It has always been a heated discussion on the strategies of "Domestication" or "Foreignization" in the related research field. Venuti clearly stresses that Domestication and Foreignization are not opposite strategies and there is no absolute boundary between the two strategies. To some extent, they overlap each other, because Foreignization is also implemented in the target language culture (Guo, 2008). The ultimate goal of translation is to promote cultural exchanges between the two languages, regardless of advantages and disadvantages of Domestication and Foreignization strategies. Neither Domestication nor Foreignization can solve all translation problems, and thus the strategy of flexibly adopting Domestication and Foreignization is the best way to solve translation problems (Chen, 2018).

\section{B. An Overview of Publicity Texts}

According to Oxford Advanced Learner's English-Chinese Dictionary (2002, p.1197), "publicity" is defined as "providing information in order to attract attention". In Longman Dictionary of Contemporary English (1995, p.1139), "publicity" refers to "the attention that someone or something gets from the newspapers, television and so on". In The Merriam-Webster Dictionary (2004, p.583), "publicity" means "information with news value issued to gain public attention or support". While Collins Cobuild English-Chinese Dictionary (2002, p.1556) defines "publicity" as "information or attentions intended to attract the public's attention to someone or something". As can be seen from the above-mentioned definitions, publicity includes different categories. In a narrow sense, publicity refers to those publicity activities planned by publicity authorities. In a broad sense, publicity is needed in any industry that has communication and contacts with foreigners, foreign affairs, international trade, finance, education, tourism and so on (Epstein, Lin, Shen, 2000). Professor Zeng Lisha (2007) also proposes that publicity texts include "introduction on politics, economy, national defense, science, technology, and education; notice on local government's policies and external exchange activities; investment promotion advertising, tourism advertising, etc." (Cao, 2014)

External publicity has been playing an essential role in cross-cultural communication. With the opening-up policy and the acceleration of economic globalization, China enjoys rapid development and close connection with other countries. Intangible cultural heritage, as the core of "cultural soft power" showing the cultural quality and spiritual outlook of a city, plays an essential role in the external publicity. Therefore, culture-specific items in the publicity texts of the intangible cultural heritage would be specially studied.

\section{An Overview of Intangible Cultural Heritage and Culture-specific Items}

At the General Conference on 17 October 2003, the United Nations Educational, Scientific and Cultural Organization (UNESCO) adopted the Convention for the Safeguarding of the Intangible Cultural Heritage, which defines intangible cultural heritage as "the practices, representations, expressions, knowledge, skills, as well as the instruments, objects, artefacts and cultural spaces associated therewith-that communities, groups and, in some cases, individuals recognize as 
part of their cultural heritage". This intangible cultural heritage, transmitted from generation to generation, is sometimes called "living cultural heritage" and is constantly recreated by communities and groups in response to their environment, their interaction with nature and their history, and provides them with a sense of identity and continuity, thus promoting respect for cultural diversity and human creativity. In the "Convention", the "intangible cultural heritage" is manifested in the following domains: oral traditions and expressions, including language as a vehicle of the intangible cultural heritage; performing arts; social practices, rituals and festive events; knowledge and practice concerning nature and the universe; traditional craftsmanship, etc. The purposes of the "Convention" are: to safeguard the intangible cultural heritage; to ensure respect for the intangible cultural heritage of the communities, groups and individuals concerned; to raise awareness at the local, national and international levels of the importance of the intangible cultural heritage, and of ensuring mutual appreciation thereof; and to provide for international cooperation and assistance. In short, the "Convention" emphasizes that intangible cultural heritage is a "melting pot of cultural diversity" and advocates that different cultural groups can appreciate and respect each other's cultural differences, protect and enrich cultural diversity, and create conditions for interaction and dialogue among different cultural groups.

"Culture-specific item" is proposed by Spanish translator Aixila in 1996, and is defined as "certain items that appear in the text, whose function and meaning in the source text would be difficult to translate when transferred to the target text because there are no corresponding items in the cultural system of the target readers or there are different text statuses from these items" (Chang, 2004). The culture-specific items in intangible cultural heritage include proper nouns such as the names of people, places, objects, art forms, dynasties, folklore, classics, etc., as well as common expressions such as historical events, myths and legends (Chen, 2011).

As a cross-cultural communication activity, translation is a bridge to connect and spread different cultures. Intangible cultural heritage is the quintessence of a nation, which is national. At the same time, for other nations, the intangible cultural heritage of this nation is heterogeneous. Therefore, when translating intangible cultural heritage, translators should strive to spread and preserve the nationality and heterogeneity of culture. Foreignization advocates retaining the heterogeneity between the content of the source text and cultural heterogeneity, which is in line with the purpose of the "Convention for the Satefuarding of the Intangible Cultural Heritage", namely promoting cultural diversity and dialogue. However, as the Guangzhou's publicity texts contain a large number of culture-specific items, excessive foreignization would make it difficult to understand the translation, leading to readers' losing interest in intangible cultural heritage. In view of this, this paper would explore the English translation methods of culture-specific items in the publicity texts of Guangzhou's intangible cultural heritage in the light of Foreignization and Domestication, aiming to provide reference for the translation researches and practice of intangible cultural heritage in Guangzhou and other cities.

\section{Previous Studies of the Chinese-English Translation of Intangible Cultural Heritage in Guangzhou}

In recent years, Guangzhou has attached great importance to the protection of intangible cultural heritage and has carried out fruitful exploration and practices in various aspects. To effectively bring its culture to the whole world and create a culture and tourism highland in Guangdong-Hong Kong-Macau Greater Bay Area, Guangzhou must carry out effective cross-cultural communication with the help of Chinese-English translation of intangible cultural heritage. However, through a lot of market researches and literature researches, it is found that there are few translations of intangible cultural heritage in Guangzhou, which only appear sporadically on individual publications or websites such as "Intangible Cultural Heritage of China (English version)", "Chinese Intangible Cultural Heritage-100 Episodes of Large-scale TV Documentary", "China Daily (English version)" and "China Culture (English version)". There is not even any English introduction of national and provincial intangible cultural heritage items on the website of the Guangdong Provincial Cultural Museum.

In addition, studies on the C-E translation of Guangzhou's Intangible Cultural Heritage are scarcely found, with only quite few researches on "Yueju Opera" mainly focusing on the analysis of translation strategies such as the titles and lines of some famous programs (See for example Chen, 2020; Huang, Zeng, 2019; Li, Zeng, 2018). The lack of C-E translation practices and researches has slowed down the pace of promoting Guangzhou's cultural essence to the world and restricted the in-depth development and marketization of Guangzhou's intangible cultural heritage. As intangible cultural heritage is the core of Guangzhou's "cultural soft power", the quality of its C-E translation directly determines the effect of promoting Guangzhou's culture to the world. Therefore, the translation study of Guangzhou's intangible cultural heritage is extremely urgent.

\section{The ChINESE-ENGLISH TRANSLATION METHODS OF CULTURE-SPECIFIC ITEMS IN PUBLICITY TEXTS OF GUANGZHOU'S INTANGIBLE CULTURAL HERITAGE}

A large number of culture-specific items are involved in the publicity texts of Guangzhou's intangible cultural heritage, and thus it is necessary to retain the cultural heterogeneity of the source language while taking into account the understanding and acceptance of the target readers. Under the guidance of Foreignization and Domestication, the following methods can be adopted to translate the culture-specific items.

\section{A. Literal Translation}

Human practice and cognition of the external world has commonality and universality. Based on this, literal 
translation, as the most direct translation method, can not only retain the ideological content of the source text, but also retain its formal characteristics and heterogeneity. For example, some culture-specific items can be literally translated as follows.

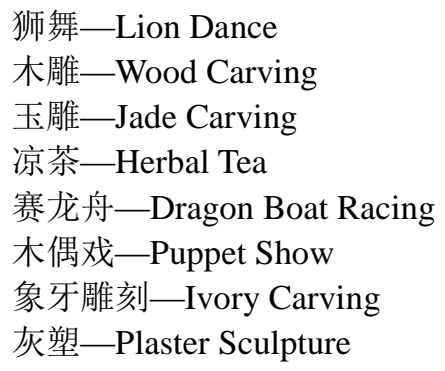

\section{B. Literal Translation plus Transliteration}

Since most of the names of intangible cultural heritage in Guangzhou are composed of place names plus category words, category words can be translated literally, and place names or words with Chinese characteristics can be transliterated. For example, some culture-specific items can be translated as follows.

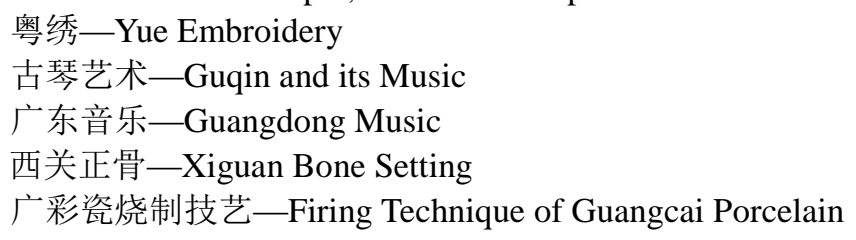

\section{Transliteration plus Explanation}

Transliteration is often used to translate names with distinctive ethnic characteristics, which helps to retain the linguistic and cultural characteristics of the source language. However, excessive transliteration can easily lead to excessive foreignization. Therefore, the method of transliteration plus explanation can be adopted when culture-specific items first appear. For example, the folk belief “波罗诞” refers to the traditional folk belief that is held regularly in Nanhai Temple (commonly known as the Boluo Temple) in the Huangpu District of Guangzhou to worship the Nanhai God. The time of the temple fairs is set around the birthday of the Nanhai God, which means God of the South Sea. If it is directly transliterated into "Boluodan Belief and Customs", the target readers cannot understand what "Boluodan" really refers to. Proper explanation is needed here and it can be translated into "Boluodan Belief and Customs (God of the South Sea)".

\section{Literal Translation plus Explanation}

Literal translation is the most direct translation method. However, sometimes target readers can not categorize some culture-specific items only by their literal names. For example, if “家具制作技艺” is literally translated into “Furniture Making Technique", target readers cannot understand the essence of Guangzhou's furniture making technique. The "furniture" here refers to the hardwood furniture with Cantonese style, which is quite different from those manufactured in other countries. Hence proper explanation is needed to make up the information. It can be translated into "Making Techniques of Cantonese-style Hardwood Furniture".

\section{E. Transliteration plus Category Words}

At the translation seminar of Shanghai International Studies University in 1997, Professor Qiu Maoru proposed that we could choose appropriate translation methods in seven ways to establish "cultural equivalence", which included transliteration plus category words (Chen, 2011). For example, the method of transliteration plus category words is adopted in the English translation of “粤剧” (Yueju Opera) listed on the UNESCO Human Intangible Cultural Heritage. Here "Yue" is short for Guangdong province and the word "opera" is used to define this item. Therefore, for some culture-specific items with distinctive local characteristics, it is necessary to add category words on the basis of transliteration to help target readers better understand intangible cultural heritage. Some culture-specific items can also adopt this method in translation. For example, “广东汉剧” can be translated into “Guangdong Hanju Opera” and “广州 咸水歌” can be translated into “Guangzhou Xianshuige Folk Song”.

\section{F. Transliteration or Literal Translation plus Intra-text Explanation}

Transliteration and literal translation are simple and straightforward, which help to preserve the heterogeneity of the source culture. However, sometimes simple transliteration or literal translation cannot effectively convey its cultural connotation. Therefore, an explanation in line with the cognition of the target readers can be appropriately added to the English translation. Take the introduction of "Guangdong Puppet Show" on the website of China Intangible Cultural Heritage for example:

“广东木偶艺术在元朝时由浙、闽传入。清末民初, 木偶戏活跃于广州街头, 主要在城隍庙、荔湾西关黄沙一 
带和乡村神诞庙会演出。广州成为广东木偶戏艺术的弘扬之地。”

If “元朝” and “清末民初” in the text are only literally translated or transliterated into "Yuan Dynasty” and "the end of the Qing Dynasty and the beginning of the Republic of China", which is beyond the cognition of target readers, the readers could not really understand the long history of "Guangdong Puppet Show". Thus, it is suggested that the corresponding years should be added after the dynasties, such as "Yuan Dynasty (1206-1368)". The whole paragraph can be translated as follows:

"Guangdong puppet art was introduced from Zhejiang and Fujian province in the Yuan Dynasty (1206-1368). At the end of the Qing Dynasty (1616-1912) and the beginning of the Republic of China, puppet shows were active in the streets of Guangzhou, mainly performed in the Chenghuang Temple, the Huangsha area of Liwan Xiguan and rural temple fairs. Guangzhou has become a place to promote the art of Guangdong puppet show."

\section{G. Transliteration plus Free Translation}

The "Convention for the Satefuarding of the Intangible Cultural Heritage" stipulates that the dissemination of intangible cultural heritage should not only retain the heterogeneity, but also promote dialogue and exchanges. Therefore, transliteration that can retain the language characteristics of the source culture plus free translation that meets the way of thinking and cognition of target readers can be adopted. Take the introduction of "Guqin and its music" on the website of China Intangible Cultural Heritage for example:

“古琴有七根弦, 十三个徽, 通过十种不同的拨弦方式, 演奏者可以演奏出四个八度。古琴的演奏有三种基本 技巧: 散、按、泛。”

Guqin, as the first of the necessary qualities of ancient Chinese literati, "Qin, chess, calligraphy, and painting", is an elite art of nobility and ordinary people have little contact with them. Therefore, the above-mentioned playing techniques “散”, “按” and “泛” cannot be simply transliterated, but should be translated in line with the way of thinking and linguistic habits of target readers. Free translation with cultural equivalents as a supplementary explanation in parentheses is suggested and the C-E translation of these playing techniques on the website of China Culture as follows sets a good example for the translation of intangible cultural heritage.

"The guqin has seven strings and thirteen marked pitch positions. By attaching the strings in ten different ways, players can obtain a range of four octaves. The three basic playing techniques are known as san (open string), an (stopped string) and fan (harmonics)."

\section{Suggestions on the C-E Translation of GuAngZhou’s InTANGible Cultural Heritage}

In recent years, Guangzhou has carried out fruitful exploration and practice in the protection and promotion of intangible cultural heritage. However, to effectively promote its culture to the world and improve the marketization and economicization of intangible cultural heritage, the quality of its C-E translation should be guaranteed. How to improve the quality of translation of intangible cultural heritage can not only rely on translators, but also require the cooperation among the government, the society and people.

First, the government should play a leading role in various aspects such as accelerating the construction of intangible cultural heritage platforms, especially the Chinese-English bilingual platforms, producing various forms of documentaries on intangible cultural heritage, and promoting intangible cultural heritage through the Internet and mobile social media.

Second, the awareness of protecting intangible cultural heritage and cross-cultural communication should be enhanced. All kinds of activities for citizens can be organized to promote intangible cultural heritage, such as "intangible cultural heritage going into scenic spots", where more intangible cultural heritage tourism routes can be made and the quality of the Chinese-English translation of intangible cultural heritage culture and public signs in scenic spots can be improved; "intangible cultural heritage going into the campus", where more speaking contests and other activities on intangible cultural heritage can be organized, more teachers and students can be encouraged to participate in cultural exchanges. At the same time, more international activities such as cultural exhibitions on intangible cultural heritage can be held and all sectors of the society can be encouraged to participate in the practice of Chinese-English translation of intangible cultural heritage and give valuable suggestions accordingly.

Third, the training of translators of intangible cultural heritage should be attached greater importance to, and the cooperation between the government and the universities should be strengthened to cultivate more translators with strong bilingual and cross-cultural capabilities and a strong sense of responsibility, providing them with more opportunities for translation practice.

\section{CONCLUSION}

The Chinese-English translation of intangible cultural heritage is a kind of cultural translation, which can help the intangible cultural heritage of Guangzhou to enter the international market based on local culture. While emphasizing the characteristics and identification of its local traditional culture, it is necessary not to violate the speech norms of the target language culture and to achieve the effect of "seeking common ground while reserving differences", i.e., foreignization at the cultural level and domestication at the language level (Liu, 2012). Under the guidance of 
Domestication and Foreignization, this study explores 7 Chinese-English translation methods of culture-specific items in Guangzhou's intangible cultural heritage publicity texts, including literal translation, literal translation plus transliteration, literal translation plus explanation, transliteration plus explanation, transliteration plus category words, transliteration plus intra-text explanation and transliteration plus free translation. Some suggestions are also given aiming to help promote Guangzhou's culture to the world, provide reference for the researches and practice of intangible cultural heritage in Guangzhou and other cities, and provide implications for foreign language teaching and training.

\section{ACKNOWLEDGEMENTS}

This study is supported by Maoming Social Sciences Association Grant (grant number: 2019YB09) and Department of Science and Technology of Maoming (grant number: 2019431)

\section{REFERENCES}

[1] Cao Tingting. (2014). On Strategies for Translation of Publicity Materials Concerning Overseas Chinese Affairs from the Perspective of Peter Newmark's Translation Theory. Master's Thesis, Guangdong University of Foreign Studies.

[2] Chang Nam Fung. (2004). A Critical Introduction to Aixela's Strategies for Translating Culture-specific Items. Chinese Translators Journal, 1, 18-23.

[3] Chen Fangrong. (2011). Difficulties and Countermeasures in English Translation of China's Intangible Cultural Heritage. Chinese Science \& Technology Translators Journal, 2, 41-44.

[4] Chen Wen. (2018). Studies on Domestication and Foreignization in China's Publicity Translation-Based on White Papers within the $13^{\text {th }}$ Five-Year Plan Period. Master's Thesis, Dalian University of Technology.

[5] Chen Yu. (2020). An Analysis of the Status Quo of the Research on the English Translation of Lingnan Yue Opera. English Square, 18, 18-20.

[6] Collins Cobuild Chinese-English Dictionary. (2002). Shanghai: Shanghai Translation Publishing House

[7] Convention for the Safeguarding of the Intangible Cultural Heritage 2003.2 (2003). http://portal.unesco.org/en/ev.php-URL_ID=17716\&URL_DO=DO_TOPIC\&URL_SECTION=201.html. (accessed 19/2/2021).

[8] Epstein, Lin Wusun, Shen Suru. (2000). Call for Attention to Foreign Language Work in External Publicity. Chinese Translators Journal, 6, 2-4.

[9] Guangdong Provincial Government. http://gd.people.com.cn/n2/2020/1020/c123932-34360364.html. (accessed 19/2/2021).

[10] Guangdong Puppet Show. http://www.ihchina.cn/project_details/13451/ (accessed 19/2/2021).

[11] Guo Jianzhong. (2000). Venuti and His Deconstructionist Translation Strategy. Chinese Translators Journal, 1, 49-52.

[12] Guo Jianzhong. (2008). An Interview with Venuti. Chinese Translators Journal, 3, 43-46.

[13] Guqin and its music. http://en.chinaculture.org/2020-12/18/content_1487744.htm (accessed 19/2/2021).

[14] Guqin and its music. http://www.ihchina.cn/directory_details/11704 (accessed 19/2/2021).

[15] Huang Yingxue, Zeng Yanwen. (2019). A Study of the Translation Strategies of Cantonese Opera under the Background of One Belt and One Road Initiative. Sichuan Drama, 1, 40-44. Cultural Heritage

Office. https://www.lcsd.gov.hk/CE/Museum/ICHO/en_US/web/icho/what_is_intangible_cultural_heritage.html (accessed 19/2/2021).

[17] Jiang Zhihui. (2010). A Study of the Dissemination of Folk Culture from the Perspective of Foreignization-with Focus on Folk Culture Translation in Zhejiang Province. Chinese Science \& Technology Translators Journal, 2, 49-51.

[18] Lefevere A. (1992). Tanslation/ History/ Culture. London and New York: Routedge.

[19] Li Yanxia, Zeng Yanwen. (2018). The Translation and Evolution of Lingnan Cantonese Opera from the Perspective of Cross-cultural Communication. Sichuan Drama, 9, 18-23.

[20] List of China's Intangible Cultural Heritage. http://www.ihchina.cn/project.html?tid=1\&cid=440000\#sy_target1. (accessed 19/2/2021).

[21] Liu Helin. (2012). Constructing Cultural Diversity in the Translation of Chinese into Foreign languages. Chinese Science \& Technology Translators Journal, 2, 45-48.

[22] Longman Dictionary of Contemporary English. (1995). Beijing: Foreign Language Teaching and Research Press.

[23] Oxford Advanced Learner's English-Chinese Dictionary. (2002). Beijing: The Commercial Press.

[24] Shuttleworth M.\& Cowie M. (1997). Dictionary of Translation Studies. Manchester: St Jerome.

[25] Schleiermacher A. (1992). On the Different Methods of Translating. Theories of Translation: An Anthology of Essays from Dryden to Derrida. Chicago: The University of Chicago Press, 36-54.

[26] The Merriam-Webster Dictionary. (2004). Springfield: Merriam-Webster Inc.

[27] Venuti Lawrence. (1995). The Translator is invisibility-A History of Translation. London: Routledge, 179-212.

[28] Venuti Lawrence. (2001). Strategies of translation. London and New York: Routedge.

[29] Wang Dongfeng. (2002). About Domestication and Foreignization. Chinese Translators Journal, 5, $26-28$.

[30] Wu Keyan. (2011). The Translation of the Materials on Chinese Intangible Cultural Heritage and the Readers' Identification. Journal of Zhangzhou Normal University, 2, 133-139.

[31] Xu Min, Wang Junping. (2016). A Study on the English Translation of the Cultural Concept of China's Intangible Cultural Heritage. Journal of Xi' an International Studies University, 2, 108-112.

[32] Yueju Opera. http://en.chinaculture.org/2020-12/18/content_1487663.htm (accessed 19/2/2021).

[33] Zeng Lisha. (2007). On the Theoretical Construction of Pragmatic Translation System from the Perspective of Categorization of Translation Principles. Foreign Languages and Their Teaching, 7, 44-46. 
Shaohui Zheng is a lecturer of School of Foreign Studies, Guangdong University of Petrochemical Technology. She graduated from Guangdong University of Foreign Studies and got her master's degree in 2008. Her areas of specialization include applied linguistics, intercultural communication and translation. 